NBER WORKING PAPER SERIES

\title{
EFFECTS OF OVERWEIGHT ON RISKY SEXUAL BEHAVIOR OF ADOLESCENT GIRLS
}

\author{
Susan Averett \\ Hope Corman \\ Nancy Reichman \\ Working Paper 16172 \\ http://www.nber.org/papers/w16172
}

\author{
NATIONAL BUREAU OF ECONOMIC RESEARCH \\ 1050 Massachusetts Avenue \\ Cambridge, MA 02138 \\ July 2010
}

We are grateful to Asia Sikora and Julien Teitler for helpful comments and Oliver Joszt for excellent research assistance. This research uses data from Add Health, a program project directed by Kathleen Mullan Harris and designed by J. Richard Udry, Peter S. Bearman, and Kathleen Mullan Harris at the University of North Carolina at Chapel Hill, and funded by grant P01-HD31921 from the Eunice Kennedy Shriver National Institute of Child Health and Human Development, with cooperative funding from 23 other federal agencies and foundations. Special acknowledgment is due Ronald R. Rindfuss and Barbara Entwisle for assistance in the original design. Information on how to obtain the Add Health data files is available on the Add Health website (http://www.cpc.unc.edu/addhealth). No direct support was received from grant P01-HD31921 for this analysis. The views expressed herein are those of the authors and do not necessarily reflect the views of the National Bureau of Economic Research.

NBER working papers are circulated for discussion and comment purposes. They have not been peerreviewed or been subject to the review by the NBER Board of Directors that accompanies official NBER publications.

(C) 2010 by Susan Averett, Hope Corman, and Nancy Reichman. All rights reserved. Short sections of text, not to exceed two paragraphs, may be quoted without explicit permission provided that full credit, including $\odot$ notice, is given to the source. 
Effects of Overweight on Risky Sexual Behavior of Adolescent Girls

Susan Averett, Hope Corman, and Nancy Reichman

NBER Working Paper No. 16172

July 2010

JEL No. I1,J1

\section{ABSTRACT}

We use data from The National Longitudinal Survey of Adolescent Health to estimate effects of adolescent girls' overweight on their propensity to engage in risky sexual behavior. We estimate single equation, two-stage, and sibling fixed-effects models and find that overweight or obese teenage girls are more likely than their recommended-weight peers to engage in certain types of risky sexual behavior but not others. The results from this study underscore the importance of using multifaceted and contemporary measures of risky sexual behavior and have implications for the health and well-being of adolescent girls.

Susan Averett

Simon Center

Dept. of Economics

Lafayette College

Easton, PA 18042

DYHHWस DDD HWHHCX

Hope Corman

Rider University

2083 Lawrenceville Road

Lawrenceville, NJ 08648

and NBER

corman@ rider.edu
Nancy Reichman

Robert Wood Johnson Medical School

University of Medicine and Dentistry of New Jersey

97 Paterson St., Room 435

New Brunswick, NJ 08903

reichmne@umdnj.edu 
Relations with the opposite sex are important social interactions in the lives of adolescent girls. A growing literature has focused on determinants and consequences of adolescent sexual activity, and this body of work has generated much knowledge. However, the predominant focus has been on vaginal intercourse, while in reality teenagers engage in a variety of different sexual activities. For example, recent findings from the National Survey of Family Growth indicate that $54 \%$ of adolescent girls age 15-19 in the United States in 2002 had ever performed oral sex (Lindberg, Jones \& Santelli, 2008), that $11 \%$ of this same cohort had ever engaged in anal sex (Lindberg, Jones \& Santelli, 2008), and that $10 \%$ of teen females have had heterosexual oral sex but not vaginal intercourse (Mosher et al., 2005). Additionally, many studies in the existing literature focus on questions involving the timing of sexual debut or whether individuals abstain from sexual intercourse. That is, they generally do not distinguish between sexual intercourse that is particularly risky (e.g., unprotected sex with multiple partners) and that which confers much less health risk (e.g., protected sex within an exclusive relationship). The former is far from rare. For example, reports based on the 2002 and 2003 Youth Risk Behavior Surveys indicate that $11 \%$ of $9^{\text {th }}-12^{\text {th }}$ grade girls reported having had four or more sexual partners and that $17 \%$ of sexually active $15-19$ year old girls reported that they did not use contraceptives at their most recent sexual encounter (Abma et al., 2004; Kaiser Family Foundation, 2005).

Many sexual activities confer health risks and females bear the brunt of most of those risks. It is well known that unprotected vaginal intercourse is strongly associated with unintended pregnancy and sexually transmitted diseases (STDs). According to Landry and Turnbull (1997): (1) Women are more susceptible to STDs than men when they have sex with an infected partner and do not use a condom. (2) Infected women are more likely than infected men to be asymptomatic, which can lead to serious health complications. (3) With the exception of Human 
Immunodeficiency Virus (HIV), STDs may have more life-threatening consequences for women (e.g., Pelvic Inflammatory Disease, ectopic pregnancy, and cervical cancer) than for men. (4) Young women contract STDs more easily than adult women because they have fewer protective antibodies and because cervical immaturity facilitates the transmission of infections. Recent evidence from the Centers for Disease Control indicates that 1 in 4 young women between the ages of 14 and 19 in the U.S. is infected with at least one of the most common STDs (human papillomavirus (HPV), chlamydia, herpes simplex virus, and trichomoniasis) (CDC, 2010). Having multiple sexual partners is an important risk factor for STDs because many teenagers do not use condoms correctly and consistently (Santelli et al., 1998). Oral sex can also lead to transmission of STDs and most teens do not use barrier protection during oral sex (HalpernFelsher et al., 2005). Finally, the odds of contracting HIV from unprotected receptive anal intercourse are about 5 times that from unprotected vaginal intercourse (Varghesi et al., 2002; Lescano et al., 2009), and studies have found that anal intercourse among adolescents and young adults is often unprotected (Rotheram-Borus et al., 1999; Lescano et al., 2009).

Overweight has become a pressing public health issue in the United States and most other developed countries, and there is much research and policy interest in its causes and consequences. Teenage girls have not been spared from the obesity epidemic. Between the 1960s and 2003-2005, the prevalence of overweight in girls aged 12 to 19 in the U.S. increased from 4.7\% to over 17\% (National Center for Health Statistics, 2010, Table 73). A few studies in the economics literature have investigated the role of overweight as a determinant of adolescent sexual behavior, which is viewed through a lens of assortative mating in a market for sexual partners. The working hypothesis has been that as an aspect of physical appearance, overweight may be a liability in the adolescent dating market. Cawley (2001), using the National 
Longitudinal Survey of Youth (NLSY), found no evidence that body weight affects initiation of sexual activity among adolescent girls, while Cawley, Joyner \& Sobal (2006) found mixed results depending on the data set used-NLSY or The National Longitudinal Survey of Adolescent Health (Add Health). A recent study by Sabia and Rees (2010), using Add Health data, builds upon this research by estimating both two-stage and individual fixed-effects models to address the potential endogeneity of body weight. Their results confirm the Add Health findings by Cawley, Joyner \& Sobal that girls who are overweight or obese are more likely than their recommended-weight peers to delay engaging in sexual intercourse.

To date, research on the effects of overweight on sexual behavior of adolescent girls has rarely focused on risky sexual behaviors despite: (1) the high prevalence and public health importance of such behaviors; (2) sociological literature suggesting that adolescents' social behavior is strongly influenced by peer networks (which, because they attend school, are more organized and self-contained than those of most adults) and fear of social isolation (see Coleman, 1961; Bearman and Moody, 2004; Tani, Chavez and Deffenbacher,2001); and (3) economic theory suggesting that girls who are perceived (or perceive themselves) as less attractive will be more likely to engage in risky sexual behaviors--that is, move from a dating market to a market for sexual partners (the theoretical arguments are developed below). A few studies in the medical and public health literature have examined associations between body weight and risky sexual behaviors among young females (e.g., Akers et al., 2009; Wiederman \& Hurst, 1998; Eisenberg et al., 2005). Of particular note, Eisenberg et al. found that among young female college students, those with higher Body Mass Index (BMI) were more likely to engage in casual sex and to have multiple partners. 
As far as we know, only five studies of effects of adolescent female overweight on sexual behavior have gone beyond sexual intercourse in characterizing adolescent heterosexual relationships. All used Add Health, in certain cases augmented with other datasets. Halpern et al. (1999) found that more body fat was associated with a lower probability of dating, even among non-obese girls, and Halpern et al. (2005) found that for each one point increase in BMI, the probability of having a romantic relationship decreased by $6 \%$. Cawley, Joyner \& Sobal (2006), using both Add Health and the NLSY, also found that overweight girls are less likely than nonoverweight girls to date, as did Cawley (2001), and that the effect of overweight on dating appears to be more negative than that of overweight on sexual intercourse. Finally, Cheng \& Landale (2010) found that compared to their recommended-weight peers, overweight adolescents (males or females) have significantly later onset of first sexual intercourse and are more likely to enter early adulthood without any intimate relationship experience (defined as romantic relationships in which sexual intercourse occurs). None of these studies explicitly investigated whether girls who are shut out of the dating market because they are overweight move to a market for risky sexual encounters.

In this paper, we use data from the Add Health study to investigate effects of adolescent girls' weight on their propensity to engage in risky sexual behaviors. We focus on behaviors that have adverse effects on physical (as opposed to mental) health because the literature reveals weak or mixed associations between risky sexual behavior and mental health (Goodson et al., 2006; Eisenberg et al. 2009). The behaviors of interest include having unprotected vaginal intercourse, having sex under the influence of alcohol, and having anal intercourse. Because obesity rates vary by geography and some research has found evidence of social contagion of 
overweight within social networks (Christakis \& Fowler 2007), ${ }^{1}$ we investigate the effects of not only the individual's absolute weight but also those of her weight relative to the other girls in her school. We estimate single-equation, two-stage, and sibling fixed-effects models to address the potential endogeneity of body weight.

\section{Conceptual Framework}

Sexual activity among adolescents confers both costs and benefits. As discussed above, the costs are higher for sex that is risky and girls face higher risks than boys. Cawley, Joyner and Sobal (2006) present a conceptual framework that can be expanded to explain why girls may engage in risky sex despite the costs. In their formulation, the market for dating is not necessarily the same as the market for sex, and: (1) individuals derive utility from sex, from dating, and from one's reputation; (2) utility derived from sex, dating, and one's reputation are all functions of the attractiveness of one's partner; and (3) overweight or obesity is a proxy for attractiveness. A difference between dating and sex is that the former is more public (i.e., others can observe the attractiveness of the partner), whereas the latter generally occurs in private (i.e., others are less likely to observe the partner's attractiveness). Thus, the influence of peer networks distinguishes these two markets.

Given this framework, there would be strong assortative matching in dating markets, with more attractive teens being more desirable partners. A teen would be unwilling to match with an unattractive teen because the expected utility from the match would be lower than that with an attractive person and because such a match would compromise one's reputation. Assortative mating would be less pronounced in the market for sex than in the dating market because sex is more private than dating and effects on reputation among one's peers would therefore be less of

\footnotetext{
${ }^{1}$ Other research by Cohen-Cole and Fletcher (2008), using Add Health data, did not find any evidence of social contagion of overweight.
} 
an issue. Therefore, while girls who are physically unattractive may not match with an attractive male in the dating market, they may be able to make such a match in the sex market.

Boys would be more willing to match with less attractive girls in the sex market than in the dating market for two reasons. First, they may derive utility from risky sex acts, such as vaginal intercourse without a condom, which confer less risk to them than it does to girls. In a match of equally attractive girls and boys, girls would be less willing than boys to engage in risky sex since they incur greater costs and do not incur greater benefits. In order to find willing partners for risky sex, a boy may have to move to a less physically attractive match. The less attractive girl would face greater risks in the sex market than in the dating market, but these may be offset by the benefits of having a more attractive partner. Second, if having a greater number of sexual partners enhances the reputation of boys but not that of girls, attractive girls would be less available than unattractive girls in the sex market. Thus, based on the Cawley-Joyner-Sobal framework, and assuming that overweight girls have the same tastes for both sexual activity and risk as non-overweight girls, we hypothesize that girls who are overweight or obese may be more likely than their non-overweight peers to engage in risky sex. However, if the markets for dating and sex are not as distinct as the Cawley-Joyner-Sobal framework predicts, girls who are overweight or obese may engage in less of any sexual activity compared their non-overweight peers simply because they are not viewed as an attractive match. Finally, we expect that effects, if any, will be stronger when considering a girl's weight relative to that of other girls at her school than when considering her absolute weight since, based on this model, heavy girls in "heavy schools" should be less disadvantaged in the dating market than those in "light schools." 


\section{Data}

The National Longitudinal Survey of Adolescent Health (Add Health) is a nationally representative school-based sample of adolescents who were in grades 7 through 12 in 1995 . A stratified random sample of 20,745 of youth was administered a comprehensive questionnaire covering numerous aspects of their school, family and private lives. For each youth, a parent was also interviewed; in the vast majority of cases this was the mother. Currently there are four rounds of data available, 1994-1995, 1996, 2001-2002, and 2007-2008. A sample of 80 high schools and 52 middle schools from the U.S. was selected with unequal probability. Incorporating systematic sampling methods and implicit stratification into the Add Health study design ensured that this sample is representative of U.S. schools with respect to region of country, urbanicity, school size, school type, and ethnicity (see Harris et al., 2009 for more information on the research design). In our analysis we make use of Wave 2 for several reasons. First, the respondents were relatively young in Wave 1. Second, Wave 2 includes measured height and weight rather than self-reported height and weight. Lastly, Waves 3 and 4 were fielded when the respondents were no longer adolescents.

We limit our sample to girls who are at least 14 years old and who are in the $9^{\text {th }}$ grade or higher. ${ }^{2}$ Our upper age limit is 19 . Because our study focuses on risky heterosexual behaviors, we exclude teens who report a same-sex relationship in the past 18 months. We exclude girls who had missing or inconsistent information for key analysis variables as well as those with missing sample weights.

We use three different analysis samples. The first sample (the "full sample") includes all girls with valid values for the analysis variables $(\mathrm{N}=5,198)$. The second sample consist of girls who are sexually active, defined broadly as those who have engaged in genital fondling, anal

\footnotetext{
${ }^{2}$ We exclude those below $9^{\text {th }}$ grade because the survey did not ask some relevant questions to those below $9^{\text {th }}$ grade.
} 
intercourse, and/or vaginal intercourse with a boy or man $(\mathrm{N}=3,618$, about $70 \%$ of the full sample). ${ }^{3}$ The third sample consists of girls who have had vaginal intercourse at least once in their lives ( $\mathrm{N}=2,648$, a bit over half of the full sample). Thus, girls who have had sex but not vaginal intercourse represent a sizable group that may be at high risk but typically overlooked in studies of teenage sexual behavior. Characteristics of all three analysis samples are presented in Table 1.

Measures of Sexual Behavior

We consider the general outcomes of ever having had vaginal intercourse and ever having had any sex (as defined for our second sample), but are particularly interested in the following measures of risky sexual behavior: having had vaginal intercourse without using a condom every time (past 18 months), ${ }^{4}$ having had sex while under the influence of alcohol (past 12 months), ${ }^{5}$ and having ever had anal intercourse. ${ }^{6}$ As discussed earlier, anal intercourse imparts high risks for contracting STDs, and most teens do not use condoms during anal intercourse. All of the measures of sexual behavior are based on respondents' self reports. ${ }^{7}$

As shown in Table 1, about half of all girls have had vaginal intercourse without using a condom every time. Seventy percent have had sex considering our broader definition (genital fondling, anal intercourse, or vaginal intercourse). Among girls who have had vaginal intercourse, $94 \%$ reported not having used a condom every time. These figures indicate that the majority of teenage girls who have vaginal intercourse put themselves at significant risk for

\footnotetext{
${ }^{3}$ Unfortunately, although oral sex is a very prevalent behavior among high school students, neither Wave 1 nor Wave 2 of the Add Health survey asked any questions specifically about oral sex.

${ }^{4}$ As discussed later, we explore less stringent definitions of vaginal intercourse without a condom.

${ }^{5}$ The specific question was: "Did you get into a sexual situation that you later regretted because you had been drinking?"

${ }^{6} \mathrm{We}$ were unable to investigate having multiple sexual partners as a risky behavior because the survey instrument asked only about three different partners with whom the respondent had been in a relationship.

${ }^{7}$ Add Health used Computer Assisted Personal Interviewing in order to minimize underreporting of sensitive information.
} 
STDs. Of girls who have had any sex, 11 percent have done so under the influence of alcohol and later regretted it. Nine percent of all girls have ever had anal intercourse. Of the girls who have had sex, broadly defined, $13 \%$ had ever engaged in anal intercourse, and of those who have ever had vaginal intercourse, almost 1 in $5(17 \%)$ had ever had anal intercourse.

\section{Measures of Body Weight}

In our main analyses, we characterize overweight two different ways: First, we use a dichotomous indicator for overweight or obesity that is set equal to one if a girl's BMI was above the $85^{\text {th }}$ percentile. In the same models, we also include a dichotomous indicator for whether she was underweight (BMI below the $5^{\text {th }}$ percentile). These cutoffs are recommended by the Centers for Disease Control (CDC) ${ }^{8}$ In other models, we use a dichotomous indicator for relative overweight or obesity that is set equal to one if a girl's BMI is higher than the $85^{\text {th }}$ percentile for the girls in her school. In those models, we also include an indicator for whether the girl's BMI was less than the $5^{\text {th }}$ percentile for the girls in her school. In supplemental analyses for both absolute and relative weight, we use separate indicators for overweight and obesity using the $85^{\text {th }}$ and $95^{\text {th }}$ percentile cutoffs in addition to the indicator for underweight. We also considered BMI as a continuous measure in models of both absolute and relative weight.

Over one quarter (27-29\%) of the girls in each of the analysis samples are characterized as overweight or obese, while only $2 \%$ are classified as underweight. Girls who have had vaginal intercourse are about as likely as all girls to be overweight or obese. About $14-15 \%$ of girls in

\footnotetext{
${ }^{8}$ The standard for measuring child/adolescent weight in developed countries is based on the Body Mass Index (BMI) which is defined as the ratio of weight in kilograms over height in meters squared. Because children and adolescents are still growing, BMIs are normed by gender and age using a healthy reference population for comparison. An adolescent is considered likely to be obese if his/her BMI is over the $95^{\text {th }}$ percentile of the same age and gender cohort in the reference population, overweight if his/her BMI is above the $85^{\text {th }}$ percentile, and underweight if his/her BMI percentile is below the 5th percentile (CDC, 2000). We calculate BMI percentiles using the Nutstat module of the CDC's Epi-Info software. This program also flags individuals with biologically implausible BMI values. After deleting individuals with missing values on our outcome measures implausible BMIs resulted in the removal of two individuals from our sample.
} 
each of the analysis samples are in the heaviest $15 \%$ of girls in their school, again indicating that heavy girls are about equally as likely as their recommended-weight peers to be sexually active.

\section{Covariates}

The rich information available in the Add Health dataset allows us to control for numerous individual and family characteristics that may be associated with both body weight and sexual behavior. These measures are listed in Table 1. In all models, we control for the girl's age (in months), family structure (only child in household, versus not; lives with one parent, lives with family but no parents, and lives with two parents one of whom is not biological, with each of the three compared to lives with both biological parents), the reporting parent's age (in years), an indicator for missing parent's age, the reporting parent's education (some college, high school graduate, less than high school graduate, and parent's education missing, all compared to college graduate), each parent's occupation (less than managerial or professional, and parent's occupation missing, both compared to managerial or professional), each parent's employment (employed, versus not employed), public assistance (family relies on public assistance and missing public assistance, both compared to does not rely on public assistance), the girl's religious service attendance (at least once per month, less than once per month, and missing, all relative to never), time (in years) since menarche, time (in days) since Wave 1 interview, race/ethnicity (non-Hispanic black, Hispanic, and other non-white, all relative to non-Hispanic white), and urban and rural residence (both compared to suburban). Family structure is included to capture the potential effects of siblings in the household, supervision when not in school, and parental investments in the focal child. Parents' age, education, occupations, employment, and public assistance are included as indicators of socioeconomic status. Time since menarche captures physical maturity, which has been shown to be related to both obesity (Ahmed et al., 
2009) and initiation of sexual activity (Udry, 1979). Religious service attendance is included as a control because adolescents who are particularly religious may choose to be sexually abstinent. We control for the time between interviews because some of our outcome questions are predicated on such timing. We control for race/ethnicity because there are known racial/ethnic differences in both body weight and adolescent sexual activity. The urban and rural indicators are included to control for geographic variations in overweight and sexual behavior. Finally, we include indicators for the school the teen attended to allow us to control for aspects of the school environment that may be associated with both body weight and sexual behavior.

There are few differences in characteristics across samples. Exceptions include family structure (being the only child in the household, living with one parent, and living with family but no parents all increase the likelihood of having had any sex and having had vaginal intercourse), public assistance (which is weakly but positively related to having had any sex), and religious attendance (which is negatively associated with having had any sex).

\section{Estimation Strategy}

The main challenge in estimating the effects of body weight on sexual behavior is the potential for unobserved heterogeneity. That is, any observed associations may reflect unobserved characteristics associated with both weight and behavior. To address this methodological challenge, we employ four different estimation strategies. First, we estimate linear probability models that control for an extensive set of covariates, including school fixed effects which account for differences in social environments and norms across schools, and assess patterns across different analysis samples and characterizations of body weight as described earlier as well as across models with different sets of covariates. We use linear probability models to facilitate comparison of the single equation results to our two-stage least 
squares results, as well as to the extant literature (e.g. Sabia \& Rees, 2010).Our second strategy

is to estimate two-stage models that use (measured) overweight or obesity of the girl's (full

biological, half biological, or non-biological) sibling of either sex (from the Add Health sibling sample) and (self-reported) obesity of her reporting parent as identifiers, a general approach taken by Sabia and Rees (2010). This approach characterizes a girls' body weight solely on the basis of shared genetic and/or environmental aspects of her family (as measured by sibling and parent body weight) that should be associated with her own weight but not with potentially confounding unobserved individual level characteristics. These two-stage models also control for possible reverse causality. Third, we estimate sibling fixed-effects models that compare full biological sisters (also using the sibling sample). This strategy, to the extent that it is successful, nets out shared unobserved genetic and environmental influences on obesity within families that may also be associated with risky sexual behavior. It thus captures individual differences across teens within families. Fourth, we directly test for one potential cause of unobserved heterogeneity-taste for risk. ${ }^{9}$ While no one approach is perfect, together they provide a cautious and careful examination of the effects of teenage girls' body weight on their risky sexual behavior.

\footnotetext{
${ }^{9}$ In theory, one way to further address this issue would be to capitalize on the longitudinal nature of the Add Health data by estimating individual fixed effects models. However, Waves 1 and 2 are a mere one year apart and the measures of height and weight in Wave 1 are self-reported. Furthermore, it is far from clear that whatever unobserved heterogeneity might exist would be constant over time. Adolescents experience a myriad of physical and emotional changes as they mature, and it is unlikely that these changes would be time invariant. Sabia and Rees (2010) estimated individual fixed effects models using self-reported height and weight across waves in Add Health and found small and insignificant effects of overweight or obesity on whether a girl had ever had sexual intercourse. The authors speculated that the weak and significant associations in this specification were due, at least in part, to insufficient person-specific variation across the weight categories between waves.
} 


\section{Results}

\section{Linear Probability Models}

Table 2 present results from linear probability models for each of the three analysis samples. Columns $a$ and $b$ present estimates from models of sexual activity and columns $c$ through $e$ (highlighted in bold) present estimates from models of risky sexual behavior. In addition to our overweight or obesity variable, all models control for the covariates listed in Table 1, school indicators, and whether the girl was underweight (for the models estimating the effects of overweight or obese) or whether the girl's BMI was less than the $5^{\text {th }}$ percentile for her school (for the models using the girl's relative weight). ${ }^{10}$

In the first two rows, we present results for the full sample of girls using the absolute (Row 1) and relative (Row 2) measures of overweight or obesity. The estimates can be interpreted as follows: The marginal effect of overweight or obese on vaginal intercourse without a condom is -.077 , indicating that being overweight or obese reduces the likelihood of ever having vaginal intercourse without using a condom in the past 18 months by 7.7 percentage points, all else equal (Row 1, Column $c$ ). The marginal effect of overweight or obesity relative to other girls in the same school is quite similar, at -.078 , indicating that being above the $85^{\text {th }}$ BMI percentile in one's school reduces the likelihood of vaginal intercourse without a condom by 7.8 percentage points (row 2, column $c$ ). Using both the absolute and relative indicators of overweight or obesity, and consistent with previous research, we find that overweight or obese girls are less likely than their recommended-weight counterparts to have had vaginal intercourse and to have had any sex. As a result, they are less likely to have had unprotected vaginal intercourse. However, overweight or obese girls are not significantly less likely to have had sex

\footnotetext{
${ }^{10}$ Full regression results for selected samples and outcomes are presented in Table 3 . In these models, which include school fixed effects, very few covariates are statistically significant.
} 
under the influence of alcohol, and once they have had vaginal intercourse, their consistency of condom use is no different from that of recommended-weight peers (Column $c$ of Rows 5 and 6). Moreover, they are more likely to have ever had anal intercourse. In the full sample, girls who are overweight or obese are about 1.4 percentage points (or about 16\%) more likely than their recommended-weight peers to have ever engaged in anal intercourse. The effect is stronger and becomes statistically significant when considering the girl's weight relative to that of other girls in her school. Girls in the top 15\% BMI of girls in their school are 2.3 percentage points (or about 26\%) more likely than their lighter peers to engage in anal intercourse.

The estimates in Rows 3 and 4 pertain to girls who are sexually active (that is, girls who have ever engaged in genital fondling, anal intercourse, and/or vaginal intercourse). We find that the negative effects of overweight or obese on having vaginal intercourse and on having vaginal intercourse without a condom are substantially attenuated but still for the most part statistically significant. In contrast, the estimated effects of overweight or obese on ever having had anal intercourse are much stronger and even more significant than those in Rows 1 and 2. Among girls who have had some sex, those who are overweight or obese are 3.2 percentage points (or about $25 \%$ ) more likely than their recommended-weight peers to have ever engaged in anal intercourse. Again, the effect is even greater ( 5 percentage points or about $38 \%$ ) for those with BMI above the $85^{\text {th }}$ percentile for girls in their school.

Rows 5 and 6 present corresponding estimates for girls who have ever had vaginal intercourse. Again, we find no evidence that sexually active overweight or obese girls take greater risks than their recommended-weight peers in terms of having unprotected vaginal intercourse or having sex under the influence of alcohol and later regretting it. However, in this sample we find even stronger effects of overweight or obesity on the probability of having ever 
had anal intercourse than we did in the "any sex" sample. Overweight or obese girls who have had vaginal intercourse are 5.1 percentage points (or 30\%) more likely than their recommendedweight peers to have ever had anal intercourse. Girls with high BMI relative to that of girls in their school are 7.3 percentage points, or almost $43 \%$, more likely than their recommendedweight counterparts to have ever had anal intercourse.

We estimated supplemental linear probability models that used alternative measures of body weight. These included (1) separate indicators for overweight and obesity, (2) BMI and BMI squared (in models of the effects of absolute weight), and (3) continuous measures of the differences from the school mean percentile (in models of the effects of relative weight). We found that the results were very consistent with those presented in Table 3. We ran models in which we re-defined the "vaginal intercourse without condom" variable as having used a condom half of the time or less (still within the past 18 months), and found the estimates were very similar to those when using the more stringent measure of having had vaginal intercourse without a condom every time. We also estimated models with additional covariates (including participation in sports) and without school indicators and found the estimates to be remarkably robust. Finally, the estimated effects of body weight were insensitive to the use of probit instead of linear probability models in specifications without school fixed-effects. The results from these and other supplemental models are not shown but are available upon request.

\section{Two-Stage Models}

The samples for the two-stage models consist of girls who had any sibling (male or female, biological or not) in the Add Health study and non-missing height and weight information for both the girl and at least one sibling ( $N=1,212$ in the "full sample"). The identifiers for the girl's overweight or obesity are whether the girl had any sibling in the sample 
who was overweight or obese and whether the parent self-reported as obese. We also include an indicator for missing parental obesity as an identifier. Table 4 summarizes the two-stage least squares (TSLS) estimates (even numbered rows) as well as those from linear probability (OLS) models (odd numbered rows) based on the corresponding two-stage samples. Each cell presents estimates from a different model. In all models, we include all of the covariates from Table 3 except indicators for underweight and the school the girl attended.

The F-statistic for the first stage, in which we estimate the girl's overweight or obesity status, is 58.3 in the "full" sample, 39.2 in the sample of sexually active girls, and 25.7 in the sample of girls who have had vaginal intercourse, indicating that our identifiers are significant predictors of girls' overweight or obesity. The tests for over-identification (Sargan and Basmann tests) also indicate that our two-stage strategy is valid, since the p-values from these tests are never below .22 (not all figures are shown). In all twelve models, Hausman tests indicated that overweight is not endogenous in the corresponding OLS models (i.e., we fail to reject the null hypothesis of exogeneity), providing support for relying on the latter. In other words, the test results indicate that any endogeneity of weight does not appreciably affect the OLS estimates, and that the OLS should be preferred to TSLS since the OLS estimates are more efficient. Cawley (2004), in research on the effect of obesity on wages, also found that OLS was preferred to two-stage models. It is noteworthy and validating that the OLS estimates for the TSLS samples are similar to or larger than the corresponding estimates in Table 3. That is, we still find that being overweight or obese is negatively and significantly related to having any sexual experience and positively related to ever having had anal intercourse.

We estimated supplementary two-stage models that used having a sibling who was overweight or obese as the sole identifier (results not shown). This set of specifications produced 
estimates of the effects of overweight or obesity on sexual behavior very similar to those from Tables 3 and 4. Our rationale for estimating these supplemental models was that parental BMI may not be a valid instrument for child BMI because it may be correlated with unobserved determinants of adolescent's sexual behavior. In the literature relating child's weight to academic achievement, parental BMI has been used as an instrument (Sabia, 2007), but Kaestner and Grossman (2008) note that its validity is questionable on the grounds that parental obesity is likely to be correlated with unmeasured educational inputs, genetic factors, and family resources that are likely to affect adolescent achievement. This may be less of an issue, however, in models of adolescent sexual activity than in models of children's academic achievement. Another advantage of not using parental obesity as an identifier is that this variable, coming from parents' self reports rather than from direct measurements of height and weight, is not well measured in the Add Health study. The disadvantage of this "single identifier" specification is that the twostage models are just-identified and we cannot perform tests of overidentification. However, the fact that our instruments passed the overidentification tests in the main two-stage models dampens our concerns about this instrument. Overall, the consistencies and patterns of estimates across the specifications so far-in terms of both direction and magnitude - are validating of our findings.

\section{Sibling Fixed-Effects Models}

The samples for the sibling fixed-effects models consist of girls with any female (full biological) siblings in the Add Health study and non-missing height and weight for both the girl and a sister ( $\mathrm{N}=566$ in the "full sample"). ${ }^{11}$ The sibling fixed-effects estimates are presented in Table 5. Each cell presents estimates from a different model. All models control for underweight

\footnotetext{
${ }^{11}$ We do not present sibling fixed-effects estimates for girls who have ever had vaginal intercourse because those analyses were based on only 200 observations and the F-statistic for the entire equation was not statistically significant.
} 
and age. Again, overweight or obese girls are found to be at elevated risk of ever having had anal intercourse, ${ }^{12}$ and the consistency of those estimates across the various model specifications (in Tables 3-5) is highly validating.

We estimated supplementary sibling fixed-effects models that were identical to those described above but also included covariates that could differ across siblings-religious attendance and years since menarche (results not shown). These factors were uniformly insignificant in explaining sexual behavior in these models and including them in the models did not change the estimated effects of being overweight or obese. Finally, we estimated a set of models that compared sisters who were twins (results not shown). The estimates were very similar in magnitude to those from the corresponding specifications in Tables 3-5, but overweight or obesity was not statistically significant in these models which were based on a maximum of 322 sets of twins.

\section{Taste for Risk as a Potential Competing Explanation}

We tested a plausible competing explanation for the observed associations between body weight and anal intercourse - that both reflect an unobserved general taste for risk (see Lescano et al., 2009). To address this issue, we ran supplemental models that include past year marijuana use and also estimated a set of models with marijuana as the outcome. Although past year marijuana use was positively related to having sex in a bivariate context (27\% of all girls used marijuana in the past year, compared to $35 \%$ of the girls who have had sex and $39 \%$ of those who have had vaginal intercourse), we found that past year marijuana use was a statistically insignificant predictor of having ever had anal intercourse and that including it in the models did not appreciably change the estimated effects of body weight on anal intercourse. In the models

\footnotetext{
${ }^{12}$ For our small sample of girls who have sisters in the sample, we no longer find that overweight or obesity reduces the likelihood of having vaginal intercourse.
} 
predicting marijuana use, body weight was an insignificant predictor. These supplemental findings suggest that a general taste for risk is not a viable competing explanation for the strong and robust associations we found between teenage girl's body weight and the likelihood that they have ever had anal intercourse.

\section{Discussion}

We investigated effects of overweight on risky sexual behaviors of teenage girls. We broadened the analysis compared to many previous studies on the topic by (1) focusing on risky behaviors as opposed to simply having vaginal intercourse, (2) considering both absolute weight and weight relative to the others in a girl's school, (3) using 3 different analysis samples-all girls, girls who have had vaginal intercourse, and girls who have had sex more broadly defined, and (4) considering a range of relevant sexual behaviors, including anal intercourse. We used rich data that allowed us to control for numerous potential confounders including age at menarche, socioeconomic status, family structure, and religious attendance. We included school fixed effects, which go a long way toward accounting for potential unobserved heterogeneity. We also estimated both two-stage and sibling fixed-effects models and found a high degree of consistency in estimates with the expected patterns across specifications.

Overall, we confirm previous research that overweight or obese girls are less likely than recommended-weight girls to be sexually active (considering both vaginal intercourse and a broader measure of sexual activity). We also found that overweight or obese girls may incur fewer risks from vaginal intercourse because they are less sexually active, but that once they become active in that regard, they expose themselves to the same risks from vaginal intercourse as other girls. 
Our most striking finding is that overweight or obese teenage girls are more likely than their recommended-weight counterparts to have ever had anal intercourse, whether sample is all girls, girls who have had sex (broadly defined), or girls who have had vaginal intercourse. The results presented here support the theoretical prediction that overweight or obese girls are at elevated risk of engaging in risky sex. That is, the findings are consistent with a scenario in which an overweight (or less attractive) girl would be willing to incur greater risks in order to attract a partner, and boys would move to less physically attractive matches in order to find willing partners for risky sex. We find evidence in support of this scenario only for anal intercourse - i.e., not for vaginal sex without a condom or sex under the influence of alcohol, both of which recommended-weight girls appear to be as willing as their overweight peers to do. The fact that we found stronger effects for relative weight (compared to other girls in the same school) than an individual's absolute weight provides further support for this scenario.

The results from this study underscore the importance of using multifaceted and contemporary measures of risky sexual behavior. If we had only considered outcomes related to vaginal intercourse, we would have concluded that overweight and obese girls are less likely than their recommended-weight peers to engage in risky sexual behavior. However, by including heterosexual anal intercourse, a risky behavior that is on the rise both in the general population and among teens (Mosher et al., 2005; Lescano et al., 2009), the conclusions are very different. Future data collection and research on the topic should broaden the focus even more by considering oral sex, a highly prevalent activity among teenage girls that we were not able to investigate using the Add Health data, and by considering whether an individual has multiple sexual partners, another risky behavior that we were not able to adequately examine for teenage girls using Add Health. 
On a broader note, this study adds to the growing knowledge about the adverse health consequences of overweight. It is well known that overweight is a risk factor for many chronic health conditions, including diabetes, hypertension, stroke, heart disease, and several types of cancer, as well as reproductive problems ranging from infertility to low birthweight (NIH, 1998). In this study, we have identified a behavioral source of health risk resulting from overweight relatively early in the lifecourse_risky sexual behavior among adolescent girls. This finding underscores the urgency of both stemming the tide of the obesity epidemic and educating teenagers about safe sex. 


\section{References}

Abma J.C., et al. (2004). Teenagers in the United States: Sexual Activity, Contraceptive use, and Childbearing, 2002. Vital and Health Statistics, Series 23, No. 24.

Ahmed, M.L., Ong, K.K., and D.B. Dunger. (2009). Childhood Obesity and the Timing of Puberty. Trends Endocrinol Metab 20(5): 237-42.

Akers, A.Y., Lynch, C.P., Gold, M.A., Chang, J.C.-C., Doswell, W., Wiesenfeld, H.C., Feng, W. and J. Bost. (2009). Exploring the Relationship Among Weight, Race, and Sexual Behaviors Among Girls. Pediatrics 124: e913-920.

Bearman, P.S., and J.M. Moody. (2004). Suicide and Friendships Among American Adolescents. American Journal of Public Health 94: 89-95

Cawley, J., Joyner, K., and J. Sobal. (2006). Size Matters: The Influence of Adolescents' Weight and Height on Dating and Sex. Rationality and Society 18: 67-94

Cawley, J. (2001). Body Weight and the Dating and Sexual Behaviors of Young Adolescents. In Social Awakening: Adolescent Behavior as Adulthood Approaches, ed. R.T. Michael, pp. 17498. New York: Russell Sage Foundation.

Cawley, J. (2004). “The Impact of Obesity on Wages.” Journal of Human Resources 39: 451474.

Centers for Disease Control. (2010). Press Release, March 11, 2008. Available at:

http://www.cdc.gov/stdconference/2008/press/release-11march2008.htm

Cheng, Y.H.-A., and N.S. Landale (2010). Teen Overweight, Weight Stigma, and Intimate Relationship Development from Adolescence to Young Adulthood. Max Planck Institute for Demographic Research Working Paper 2010-008. Available at: http://www.demogr.mpg.de/papers/working/wp-2010-008.pdf

Christakis, N.A., and J.H. Fowler. (2007). The Spread of Obesity in a Large Social Network Over 32 Years. New England Journal of Medicine 357(4): 370-379.

Cohen-Cole, E., and J.M. Fletcher. (2008). Is Obesity Contagious? Social Networks vs. Environmental Factors in the Obesity Epidemic. Journal of Health Economics 27: 1382-1387.

Coleman, J.S. (1961). The Adolescent Society. New York, NY: Free Press.

Eisenberg M.E., Neumark-Sztainer, D., and K.D. Lust. (2005). Weight-Related Issues and HighRisk Sexual Behaviors Among College Students. J Am Coll Health 54(2): 95-101. 
Eisenberg, M.E., Ackard, D.M., Resnick, M.D., and D. Neumark-Sztainer. (2009). Casual Sex and Psychological Health Among Young Adults: Is Having "Friends with Benefits" Emotionally Damaging? Perspectives on Sexual and Reproductive Health 41(4): 231-237.

Goodson, P., Buhi, E.R., and S.C. Dunsmore. (2006). Self-Esteem and Adolescent Sexual Behaviors, Attitudes, and Intentions: A Systematic Review. Journal of Adolescent Health 38(3): 310-319.

Halpern, C.T., King, R.B., Oslak, S.G., and J.R. Udry. (2005). Body Mass Index, Dieting, Romance, and Sexual Activity in Adolescent Girls: Relationships Over Time. Journal of Research on Adolescence 15(4): 535-559.

Halpern, C.T., Udry, J.R., Campbell, B, and C. Suchindran. (1999). Effects of Body Fat on Weight Concerns, Dating, and Sexual Activity: A Longitudinal Analysis of Black and White Adolescent Girls. Developmental Psychology 35(3): 721-736.

Halpern-Felsher, B., et al. (2005). Oral Versus Vaginal Sex Among Adolescents: Perceptions, Attitudes, and Behavior. Pediatrics 115: 845-851.

Harris, K.M., C.T. Halpern, E. Whitsel, J. Hussey, J. Tabor, P. Entzel, and J.R. Udry. (2009). The National Longitudinal Study of Adolescent Health: Research Design [WWW document]. URL: http://www.cpc.unc.edu/projects/addhealth/design.

Kaestner, R., \& M.Grossman. (2008). Effects of Weight on Children's Educational Achievement. NBER Working Paper \#13764.

Kaiser Family Foundation. (2005). U.S. Teen Sexual Activity. Publication \#3040-02. Available at: http://www.kff.org/youthhivstds/upload/U-S-Teen-Sexual-Activity-Fact-Sheet.pdf

Landry, D.J., and W. Turnbull. (1997). Issues in Brief: Sexually Transmitted Diseases Hamper Development Efforts. Available at: http://www.guttmacher.org/pubs/ib_std.html

Lescano, C., Houck, C.D., Brown, L.K., Doherty, G., DiClemente, R.J., Fernandez, M.I., Pugatch, D., Schlenger, W.E., and B.J. Silver. (2009). Correlates of Heterosexual Anal Intercourse Among At-Risk Adolescents and Young Adults. American Journal of Public Health 99(6): 1131-1136.

Lindberg, L, Jones, R., and J. Santelli. (2008). Non-Coital Sexual Activities Among Adolescents. Journal of Adolescent Health 43(3): 231-238.

Mosher W.D , Chandra, A., and J. Jones (2005). Sexual Behavior and Selected Health Measures: Men and Women 15-44 Years of Age, United States, 2002. Advance Data from Vital and Health Statistics, No. 362. 
National Center for Health Statistics. (2010). Health United States, 2009. Hyattsville, MD.

National Institutes of Health. (1998) Clinical Guidelines on the Identification, Evaluation, and Treatment of Overweight and Obesity in Adults: NIH Publication, No. 98-4083.

Rotheram-Borus, M.J., Marelich, W.D., and S. Srinivasan. (1999). HIV Risk Among Homosexual, Bisexual, and Heterosexual Male and Female Youths. Arch Sex Behav 28: 159177.

Sabia, J. (2007). The Effect of Body Weight on Adolescent Academic Performance. Southern Economic Journal 73(4): 871-900.

Sabia, J., and D. Rees. (2010). The Effect of Body Weight on Adolescent Sexual Activity. Unpublished working paper.

Santelli, J.S., Brener, N.D., Lowry, R., Bhatt, A., and L.S. Zabin. (1998). Multiple Sexual Partners Among U.S. Adolescents and Young Adults. Family Planning Perspectives 30(6): 271275.

Tani, C.R., Chavez, E.L., and J. L. Deffenbacher. (2001). Peer Isolation and Drug Use Among White Non-Hispanic and Mexican American Adolescents. Adolescence 36: 127-139.

Udry, J.R. (1979). Age at Menarche, at First Intercourse, and at First Pregnancy. Journal of Biosocial Science 11(4): 433-441.

Varghese, B., Maher, J.E., Peterman, T.A., Branson, B.M, and R.W. Steketee. (2002). Reducing the Risk of HIV Transmission: Quantifying the Per-Act Risk for HIV on the Basis of Choice of Partner, Sex Act, and Condom Use. Sex Transm Dis 29: 38-43.

Wiederman, M.W., and S.R. Hurst. (1998). Body Size, Physical Attractiveness, and Body Image Among Young Adult Women: Relationships to Sexual Experience and Sexual Esteem. Journal of Sex Research 35(3): 272-281. 


\section{Sexual Behaviors}

\section{Sample 1: \\ All girls}

$\mathrm{N}=5,198$

Any sex

(as defined for Sample 2)

Ever had vaginal

intercourse

Vaginal intercourse w/o condom

Sex under influence of alcohol and regretted it

Ever had anal intercourse

Weight Measures

Overweight or obese

$\left(\mathrm{BMI}>85^{\text {th }}\right.$ percentile)

Underweight

$\left(\mathrm{BMI}<5^{\text {th }}\right.$ percentile)

$\mathrm{BMI}>85^{\text {th }}$ percentile in school

$\mathrm{BMI}<5^{\text {th }}$ percentile in school

.70

.51

.73

.69

.94

.11

.12

.09

.13

.17

.02

.02

.02

.15

.14

.14

.05

.05

.05 


\section{Covariates}

Age in months, mean

198.56

(15.50)

Only child in household

Lives with 1 parent

Lives with family but no parents

Two parents but one nonbiological

Parent's age, mean, in years

41.89

(6.07)

.14

.21

Parent's education: some college

Parent's education: high school

Parent's education: $<$ high school

Parent's education missing

Father's occupation:

$<$ managerial/professional

Father's occupation missing

Father not working

Mother's occupation:

$<$ managerial/professional

Mother's occupation

missing

.51

.54

.07
200.43

202.50

(14.82)

.29

.32

.14

41.66

.15

.22

.32

.13

.03

.47

.49

.34

.38

.04

.04

.54

.54 
Mother not working

.14

.09

.04

.57

.19

.01

Religious attendance

missing

Years since menarche

\# days between interviews,

mean

Non-Hispanic black

Hispanic

Other non-white

Urban residence

Rural residence

.20

.36

Notes: All figures are proportions unless indicated otherwise. Standard deviations in parentheses.

.15

.11

.07

.50

.21

.01

4.59

334.79

(48.46)

(48.10)

.25

.27

.16

.18

.18

.36

.37

.24

.24 


\begin{tabular}{|c|c|c|c|c|c|c|}
\hline & & Any Sex & $\begin{array}{c}\text { Vaginal } \\
\text { Intercourse }\end{array}$ & $\begin{array}{c}\text { Vaginal } \\
\text { Intercouse } \\
\text { Without } \\
\text { Condom }\end{array}$ & $\begin{array}{c}\text { Sex Under } \\
\text { Influence of } \\
\text { Alcohol }\end{array}$ & $\begin{array}{c}\text { Anal } \\
\text { Intercourse }\end{array}$ \\
\hline & & (a) & (b) & (c) & (d) & (e) \\
\hline & & \multicolumn{5}{|c|}{ Full Sample N=5,198 } \\
\hline (1) & $\begin{array}{l}\text { Overweight or } \\
\text { obese }\end{array}$ & $\begin{array}{c}-.075 * * * \\
(.016)\end{array}$ & $\begin{array}{c}-.079 * * * \\
(.018)\end{array}$ & $\begin{array}{c}-.077 * * * \\
(.017)\end{array}$ & $\begin{array}{c}-.004 \\
(.007)\end{array}$ & $\begin{array}{c}.014 \\
(.009)\end{array}$ \\
\hline \multirow[t]{2}{*}{ (2) } & $\begin{array}{l}\mathrm{BMI}>85^{\text {th }} \\
\text { percentile in } \\
\text { school }\end{array}$ & $\begin{array}{c}-.085 * * * \\
(.021)\end{array}$ & $\begin{array}{c}-.076^{* * * *} \\
(.019)\end{array}$ & $\begin{array}{c}-.078 * * * \\
(.018)\end{array}$ & $\begin{array}{l}-.006 \\
(.009)\end{array}$ & $\begin{array}{l}.023 * * \\
(.011)\end{array}$ \\
\hline & & \multicolumn{5}{|c|}{ Sexually Active $\mathrm{N}=3,618$} \\
\hline (3) & $\begin{array}{l}\text { Overweight or } \\
\text { obese }\end{array}$ & $\mathrm{n} / \mathrm{a}$ & $\begin{array}{c}-.043 * * \\
(.020)\end{array}$ & $\begin{array}{c}-.047 * * \\
(.019)\end{array}$ & $\begin{array}{c}.005 \\
(.011)\end{array}$ & $\begin{array}{l}.032 * * \\
(.013)\end{array}$ \\
\hline \multirow[t]{2}{*}{ (4) } & $\begin{array}{l}\mathrm{BMI}>85^{\text {th }} \\
\text { percentile in } \\
\text { school }\end{array}$ & $\mathrm{n} / \mathrm{a}$ & $\begin{array}{l}-.030 \\
(.021)\end{array}$ & $\begin{array}{l}-.039 * \\
(.022)\end{array}$ & $\begin{array}{c}.008 \\
(.014)\end{array}$ & $\begin{array}{c}.049 * * * \\
(.017)\end{array}$ \\
\hline & & \multicolumn{5}{|c|}{ Ever Had Vaginal Intercourse $N=2,648$} \\
\hline$(5)$ & $\begin{array}{l}\text { Overweight or } \\
\text { obese }\end{array}$ & $\mathrm{n} / \mathrm{a}$ & $\mathrm{n} / \mathrm{a}$ & $\begin{array}{l}-.009 \\
(.011)\end{array}$ & $\begin{array}{c}.014 \\
(.013)\end{array}$ & $\begin{array}{c}.051 * * * \\
(.019)\end{array}$ \\
\hline$(6)$ & $\begin{array}{l}\mathrm{BMI}>85^{\text {th }} \\
\text { percentile in } \\
\text { school }\end{array}$ & $\mathrm{n} / \mathrm{a}$ & $\mathrm{n} / \mathrm{a}$ & $\begin{array}{l}-.017 \\
(.016)\end{array}$ & $\begin{array}{c}.014 \\
(.017)\end{array}$ & $\begin{array}{c}.073 * * * \\
(.025)\end{array}$ \\
\hline
\end{tabular}

Notes: All models include all of the covariates listed in Table 1, indicators for underweight (for models of overweight or obese) or for $<5^{\text {th }}$ percentile in school (for models of relative overweight), and school fixed effects. Coefficients are from linear probability models. Robust standard errors in parentheses. $* * * \mathrm{p}<0.01, * * \mathrm{p}<0.05, * \mathrm{p}<0.1$ 
Table 3. Full Regressions for Selected Outcomes

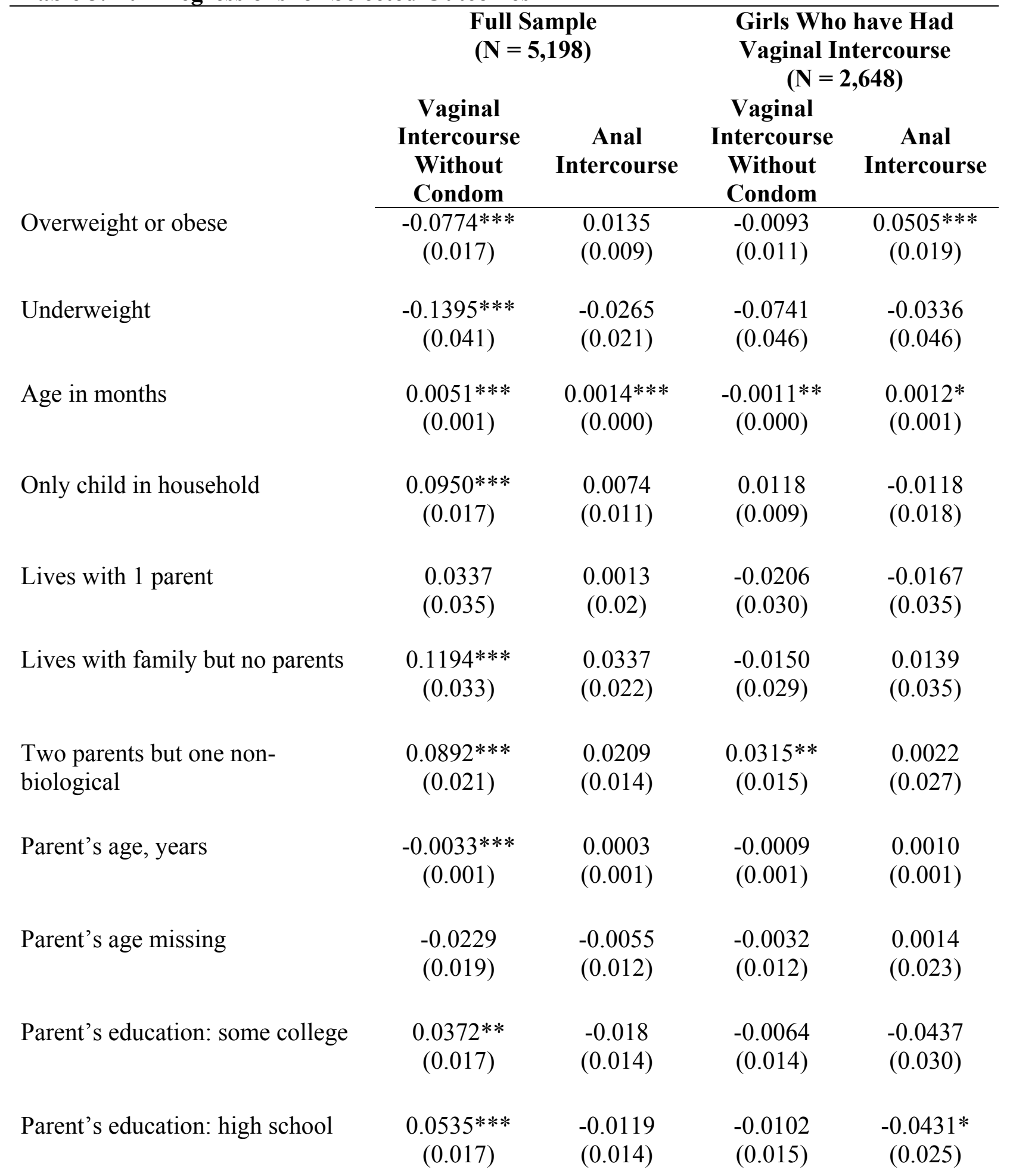




\begin{tabular}{|c|c|c|c|c|}
\hline Parent's education: $<$ high school & $\begin{array}{l}0.0375 \\
(0.026)\end{array}$ & $\begin{array}{l}-0.0238 \\
(0.018)\end{array}$ & $\begin{array}{l}-0.0239 \\
(0.019)\end{array}$ & $\begin{array}{c}-0.0579 * \\
(0.032)\end{array}$ \\
\hline Parent's education missing & $\begin{array}{l}-0.0178 \\
(0.047)\end{array}$ & $\begin{array}{l}-0.0073 \\
(0.024)\end{array}$ & $\begin{array}{l}-0.0223 \\
(0.041)\end{array}$ & $\begin{array}{l}-0.0095 \\
(0.056)\end{array}$ \\
\hline $\begin{array}{l}\text { Father's occupation: } \\
<\text { managerial/professional }\end{array}$ & $\begin{array}{l}0.0222 \\
(0.02)\end{array}$ & $\begin{array}{l}-0.0104 \\
(0.011)\end{array}$ & $\begin{array}{r}-0.0013 \\
(0.020)\end{array}$ & $\begin{array}{l}-0.0338 \\
(0.024)\end{array}$ \\
\hline Father's occupation missing & $\begin{array}{c}0.0697 * \\
(0.04)\end{array}$ & $\begin{array}{c}0.012 \\
(0.021)\end{array}$ & $\begin{array}{l}0.0401 \\
(0.033)\end{array}$ & $\begin{array}{l}-0.0088 \\
(0.039)\end{array}$ \\
\hline Father not working & $\begin{array}{l}0.0432 \\
(0.036)\end{array}$ & $\begin{array}{c}0.011 \\
(0.023)\end{array}$ & $\begin{array}{l}0.0036 \\
(0.026)\end{array}$ & $\begin{array}{l}0.0057 \\
(0.042)\end{array}$ \\
\hline $\begin{array}{l}\text { Mother's occupation: } \\
<\text { managerial/professional }\end{array}$ & $\begin{array}{l}0.0312 * \\
(0.016)\end{array}$ & $\begin{array}{l}0.0134 \\
(0.01)\end{array}$ & $\begin{array}{l}-0.0049 \\
(0.014)\end{array}$ & $\begin{array}{l}0.0106 \\
(0.020)\end{array}$ \\
\hline Mother's occupation missing & $\begin{array}{c}0.1077 * * \\
(0.042)\end{array}$ & $\begin{array}{l}0.0266 \\
(0.032)\end{array}$ & $\begin{array}{l}0.0560 \\
(0.040)\end{array}$ & $\begin{array}{l}0.0245 \\
(0.054)\end{array}$ \\
\hline Mother not working & $\begin{array}{l}0.0274 \\
(0.022)\end{array}$ & $\begin{array}{c}0.0345^{* *} \\
(0.017)\end{array}$ & $\begin{array}{l}-0.0018 \\
(0.020)\end{array}$ & $\begin{array}{c}0.0583 * \\
(0.033)\end{array}$ \\
\hline Public assistance & $\begin{array}{c}0.0334 \\
(0.03)\end{array}$ & $\begin{array}{l}0.0027 \\
(0.016)\end{array}$ & $\begin{array}{l}0.0089 \\
(0.024)\end{array}$ & $\begin{array}{l}0.0065 \\
(0.028)\end{array}$ \\
\hline Public assistance missing & $\begin{array}{l}-0.0632 \\
(0.057)\end{array}$ & $\begin{array}{l}0.0104 \\
(0.04)\end{array}$ & $\begin{array}{l}-0.0707 \\
(0.057)\end{array}$ & $\begin{array}{r}-0.0076 \\
(0.063)\end{array}$ \\
\hline $\begin{array}{l}\text { Religious services at least once } \\
\text { per month }\end{array}$ & $\begin{array}{c}-0.1146 * * * \\
(0.018)\end{array}$ & $\begin{array}{c}-0.0417 * * * \\
(0.012)\end{array}$ & $\begin{array}{l}-0.0021 \\
(0.014)\end{array}$ & $\begin{array}{c}-0.0391 * \\
(0.020)\end{array}$ \\
\hline $\begin{array}{l}\text { Religious services }<\text { once per } \\
\text { month }\end{array}$ & $\begin{array}{l}-0.0135 \\
(0.017)\end{array}$ & $\begin{array}{l}-0.0109 \\
(0.014)\end{array}$ & $\begin{array}{l}0.0069 \\
(0.015)\end{array}$ & $\begin{array}{l}-0.0134 \\
(0.022)\end{array}$ \\
\hline Religious attendance missing & $\begin{array}{c}-0.1543 * * \\
(0.078)\end{array}$ & $\begin{array}{l}0.0113 \\
(0.05)\end{array}$ & $\begin{array}{c}-0.1366^{*} \\
(0.074)\end{array}$ & $\begin{array}{l}0.0715 \\
(0.103)\end{array}$ \\
\hline Years since menarche & $\begin{array}{l}0.0338 * * * \\
(0.004)\end{array}$ & $\begin{array}{l}0.0097 * * * \\
(0.002)\end{array}$ & $\begin{array}{l}0.0032 \\
(0.004)\end{array}$ & $\begin{array}{l}0.0075 * \\
(0.005)\end{array}$ \\
\hline
\end{tabular}




\begin{tabular}{|c|c|c|c|c|}
\hline \# days between interviews & $\begin{array}{c}-0.0004^{* * * *} \\
(0.000)\end{array}$ & $\begin{array}{c}-0.0001 * \\
(0.000)\end{array}$ & $\begin{array}{l}0.0000 \\
(0.000)\end{array}$ & $\begin{array}{r}-0.0001 \\
(0.000)\end{array}$ \\
\hline Non-Hispanic black & $\begin{array}{c}0.0575 * * * \\
(0.022)\end{array}$ & $\begin{array}{l}-0.0073 \\
(0.014)\end{array}$ & $\begin{array}{c}-0.0335 * * \\
(0.017)\end{array}$ & $\begin{array}{l}-0.0293 \\
(0.028)\end{array}$ \\
\hline Hispanic & $\begin{array}{l}0.0298 \\
(0.024)\end{array}$ & $\begin{array}{c}0.0298 * * \\
(0.013)\end{array}$ & $\begin{array}{l}0.0175 \\
(0.018)\end{array}$ & $\begin{array}{l}0.0476 \\
(0.033)\end{array}$ \\
\hline Other non-white & $\begin{array}{c}-0.0567 * * * \\
(0.02)\end{array}$ & $\begin{array}{l}-0.0102 \\
(0.012)\end{array}$ & $\begin{array}{l}-0.0157 \\
(0.020)\end{array}$ & $\begin{array}{l}-0.0075 \\
(0.027)\end{array}$ \\
\hline Urban residence & $\begin{array}{c}-0.0072 \\
(0.016)\end{array}$ & $\begin{array}{l}-0.0103 \\
(0.009)\end{array}$ & $\begin{array}{c}-0.0140 \\
(0.014)\end{array}$ & $\begin{array}{l}-0.0261 \\
(0.017)\end{array}$ \\
\hline Rural residence & $\begin{array}{l}-0.0295 \\
(0.022)\end{array}$ & $\begin{array}{c}-0.0068 \\
(0.015)\end{array}$ & $\begin{array}{l}0.0030 \\
(0.013)\end{array}$ & $\begin{array}{l}-0.0096 \\
(0.028)\end{array}$ \\
\hline Constant & $\begin{array}{c}-0.7160^{* * * *} \\
(0.128)\end{array}$ & $\begin{array}{c}-0.2749 * * * \\
(0.066)\end{array}$ & $\begin{array}{c}0.8470 * * * \\
(0.106)\end{array}$ & $\begin{array}{r}-0.2352 \\
(0.160)\end{array}$ \\
\hline R-squared & 0.207 & 0.061 & 0.076 & 0.072 \\
\hline
\end{tabular}

Notes: Coefficients are from linear probability models. Robust standard errors in parentheses. All models also include school fixed effects.

$* * * \mathrm{p}<0.01, * * \mathrm{p}<0.05, * \mathrm{p}<0.1$ 
Table 4. Effects of Overweight or Obesity on Sexual Behavior of Teenage Girls with at Least One Sibling in Sample-Linear Probability (OLS) and Two-Stage (TSLS) Estimates

\begin{tabular}{|c|c|c|c|c|c|c|}
\hline & & Any Sex & $\begin{array}{c}\text { Vaginal } \\
\text { Intercourse }\end{array}$ & $\begin{array}{c}\text { Vaginal } \\
\text { Intercourse } \\
\text { Without } \\
\text { Condom } \\
\text { (c) }\end{array}$ & $\begin{array}{c}\text { Sex Under } \\
\text { Influence of } \\
\text { Alcohol } \\
\text { (d) } \\
\end{array}$ & $\begin{array}{c}\begin{array}{c}\text { Anal } \\
\text { Intercourse }\end{array} \\
\text { (e) }\end{array}$ \\
\hline & & \multicolumn{5}{|c|}{ Full Sample $(\mathrm{N}=1,212)$} \\
\hline (1) & OLS & $\begin{array}{c}-.061^{* *} \\
(.030)\end{array}$ & $\begin{array}{l}-016 \\
(.030)\end{array}$ & $\begin{array}{l}-.026 \\
(.030)\end{array}$ & $\begin{array}{c}.014 \\
(.017)\end{array}$ & $\begin{array}{l}.048 * * \\
(.020)\end{array}$ \\
\hline (2) & TSLS & $\begin{array}{l}-.050 \\
(.080)\end{array}$ & $\begin{array}{l}.001 \\
(.085)\end{array}$ & $\begin{array}{c}-.024 \\
\mathbf{( . 0 8 5 )}\end{array}$ & $\begin{array}{c}.042 \\
(.048)\end{array}$ & $\begin{array}{c}.084 \\
(.053)\end{array}$ \\
\hline (3) & OLS & $\mathrm{n} / \mathrm{a}$ & $\begin{array}{l}.022 \\
(.034)\end{array}$ & $\begin{array}{c}\text { ually Active }( \\
\mathbf{. 0 0 4} \\
\mathbf{( . 0 3 6 )}\end{array}$ & $\begin{array}{l}=840) \\
.030 \\
(.025)\end{array}$ & $\begin{array}{c}.081 * * * \\
(.030)\end{array}$ \\
\hline (4) & TSLS & $\mathrm{n} / \mathrm{a}$ & $\begin{array}{l}.045 \\
(.098)\end{array}$ & $\begin{array}{c}.001 \\
\mathbf{( . 1 0 4 )}\end{array}$ & $\begin{array}{c}.070 \\
(.070)\end{array}$ & $\begin{array}{l}.129 * \\
(.078)\end{array}$ \\
\hline (5) & OLS & $\mathrm{n} / \mathrm{a}$ & Ever Hac & $\begin{array}{c}\text { Caginal Inter } \\
\mathbf{- . 0 2 4} \\
\mathbf{( . 0 2 5 )}\end{array}$ & $\begin{array}{c}\text { Irse }(\mathrm{N}=609) \\
.034 \\
(.030)\end{array}$ & $\begin{array}{l}.086 * * \\
(.038)\end{array}$ \\
\hline (6) & TSLS & $\mathrm{n} / \mathrm{a}$ & $\mathrm{n} / \mathrm{a}$ & $\begin{array}{l}-.051 \\
(.071)\end{array}$ & $\begin{array}{c}.103 \\
(.086)\end{array}$ & $\begin{array}{c}.143 \\
(.103)\end{array}$ \\
\hline
\end{tabular}

Notes: Robust standard errors in parentheses. ${ }^{* * *} \mathrm{p}<0.01,{ }^{* *} \mathrm{p}<0.05,{ }^{*} \mathrm{p}<0.1$.

The regressors in the first stage, which predicted overweight or obese, are having a sibling who is overweight or obese, having a parent who is obese, and missing parent obesity. The F-statistic for the first stage is 58.3 for the full sample, 39.2 for the sexually active sample, and 25.7 for the sample of girls who have had vaginal intercourse. Regressors in the second stage include all covariates from Table 3 except underweight and school indicators. P-values from Sargon and Basmann over-identification tests range from .22 (vaginal intercourse without a condom in smallest sample) to .99 (anal intercourse in sexually active sample). 
Table 5. Effects of Overweight or Obesity on Sexual Behavior of Teenage Girls-Sibling Fixed-Effects Estimates

\begin{tabular}{|c|c|c|c|c|c|}
\hline & Any Sex & $\begin{array}{c}\text { Vaginal } \\
\text { Intercourse } \\
\text { (b) }\end{array}$ & $\begin{array}{c}\text { Vaginal } \\
\text { Intercourse } \\
\text { Without } \\
\text { Condom } \\
\text { (c) } \\
\end{array}$ & $\begin{array}{l}\text { Sex Under } \\
\text { Influence } \\
\text { of Alcohol } \\
\text { (d) } \\
\end{array}$ & $\begin{array}{c}\text { Anal } \\
\text { Intercourse } \\
\text { (e) } \\
\end{array}$ \\
\hline $\begin{array}{l}\text { Full Sample } \\
(\mathrm{N}=566)\end{array}$ & $\begin{array}{l}.008 \\
(.069)\end{array}$ & $\begin{array}{l}-.010 \\
(.071)\end{array}$ & $\begin{array}{c}.010 \\
(.075)\end{array}$ & $\begin{array}{l}-.018 \\
(.044)\end{array}$ & $\begin{array}{l}.060 \\
(.045)\end{array}$ \\
\hline $\begin{array}{l}\text { Sexually Active Girls } \\
(\mathrm{N}=300)\end{array}$ & $\mathrm{n} / \mathrm{a}$ & $\begin{array}{l}.004 \\
(.103) \\
\end{array}$ & $\begin{array}{c}.047 \\
(.115) \\
\end{array}$ & $\begin{array}{r}-.040 \\
(.078) \\
\end{array}$ & $\begin{array}{l}.167 * * \\
(.084) \\
\end{array}$ \\
\hline
\end{tabular}

